\title{
Organizational Socialization: Experiences of Junior Faculty in Athletic Training Education Programs
}

\author{
Stephanie M. Mazerolle \\ University of Connecticut, stephanie.m.singe@uconn.edu \\ Sara Nottingham \\ University of New Mexico, nottingham@unm.edu \\ Kelly Coleman \\ University of Connecticut, kelly.coleman@uconn.edu
}

Follow this and additional works at: https://nsuworks.nova.edu/ijahsp

Part of the Medicine and Health Sciences Commons

This Manuscript has supplementary content. View the full record on NSUWorks here: https://nsuworks.nova.edu/ijahsp/vol17/iss3/12

\section{Recommended Citation}

Mazerolle SM, Nottingham S, Coleman K. Organizational Socialization: Experiences of Junior Faculty in Athletic Training Education Programs. The Internet Journal of Allied Health Sciences and Practice. 2019 Jan 01;17(3), Article 12.

This Manuscript is brought to you for free and open access by the College of Health Care Sciences at NSUWorks. It has been accepted for inclusion in Internet Journal of Allied Health Sciences and Practice by an authorized editor of NSUWorks. For more information, please contact nsuworks@nova.edu. 


\title{
Organizational Socialization: Experiences of Junior Faculty in Athletic Training Education Programs
}

\begin{abstract}
Background: New faculty members become oriented to their new positions through numerous methods, such as institutional mechanisms as well as networking with various individuals. The process of acculturation is often complex, and best understood from a socialization framework. Role transition for the faculty member is often accomplished through professional socialization, or the experiences prior to beginning a faculty position. However, role transition also continues once the newly minted doctoral student is catapulted into employment. This dynamic, on-going process is often seen as organizational socialization. Objective: We sought to understand how Athletic Training faculty members navigate role transition, from doctoral student to faculty member during the pre-tenure years. Procedures: 19 junior Athletic Training faculty members completed semi-structured interviews to discuss their role transition and inductance into higher education. Data were analyzed following a general inductive approach. Credibility was secured through triangulation, peer review, and interpretative member checks. Results: We found that several organizational mechanisms were in place to support this time of role transition: 1) interviews, 2) orientation, 3) professional development activities, and 4) role consistency. Also, internal motivation and individual inquisitiveness supported this transition, as the junior faculty often solicited feedback or advice from others in their department to evaluate what was expected of them and how to succeed while performing their roles.
\end{abstract}

\section{Author Bio(s)}

Stephanie M. Mazerolle, PhD, ATC, FNATA is an associate professor of Athletic Training in the Department of Kinesiology at the University of Connecticut, Storrs, CT. Her areas of expertise include faculty development, mentorship and role transition.

Sara Nottingham, EdD, ATC is an assistant professor in Athletic Training at Chapman University, Orange CA. She has research expertise in clinical education and mentorship.

Kelly Coleman, MS, ATC is a doctoral student at the University of Connecticut under the advisement of Dr. Mazerolle.

\section{Acknowledgements}

The authors wish to thank Jessica Barrett for her assistance with data collection. 


\title{
IIIAHSP \\ The Internet Journal of Allied Health Sciences and Practice \\ Dedicated to allied health professional practice and education
}

Vol. 17 No. 3 ISSN 1540-580X

\section{Organizational Socialization: Experiences of Junior Faculty in Athletic Training Education Programs}

\author{
Stephanie M. Mazerolle ${ }^{1}$ \\ Sara Nottingham ${ }^{2}$ \\ Kelly Coleman ${ }^{1}$ \\ 1. University of Connecticut \\ 2. University of New Mexico \\ United States
}

\begin{abstract}
Background: New faculty members become oriented to their new positions through numerous methods, such as institutional mechanisms as well as networking with various individuals. The process of acculturation is often complex, and best understood from a socialization framework. Role transition for the faculty member is often accomplished through professional socialization, or the experiences prior to beginning a faculty position. However, role transition also continues once the newly minted doctoral student is catapulted into employment. This dynamic, on-going process is often seen as organizational socialization. Objective: We sought to understand how athletic training faculty members navigate role transition, from doctoral student to faculty member during the pre-tenure years. Procedures: Nineteen junior athletic training faculty members completed semi-structured interviews to discuss their role transition and inductance into higher education. Data were analyzed following a general inductive approach. Credibility was secured through triangulation, peer review, and interpretative member checks. Results: We found that several organizational mechanisms were in place to support this time of role transition: 1) interviews, 2) orientation, 3) professional development activities, and 4) role consistency. Also, internal motivation and individual inquisitiveness supported this transition, as the junior faculty often solicited feedback or advice from others in their department to evaluate what was expected of them and how to succeed while performing their roles. Conclusion: Two primary mechanisms were identified as socializers for the athletic training faculty member as they transitioned into their faculty roles: organizational mechanisms and individual mechanisms. Future research may broaden the scope of study by including a larger sample size, comparisons among other medical and healthcare disciplines, and a metric of organizational assimilation and socialization.
\end{abstract}

Key Words: on-boarding, role transition, higher education 


\section{INTRODUCTION}

Socialization is often described as a learning process, one that is active and allows for a person to become familiar with and aware of organizational norms, values, and culture.1,2 Socialization additionally allows individuals an opportunity to learn the expectations and roles they will fulfill in their new organization. ${ }^{3}$ The process of socialization captures two specific elements, often grounded by pre-entry to the organization (professional socialization) and entry into the workforce (organizational socialization).3,4 Pre-entry encapsulates the training one receives prior to entering the profession or organization, and in the case of the faculty member, it occurs during graduate education as well as past experiences that provided exposure to the role in the first place. Newcomers carry their personal and professional socialization experiences with them as they enter the organization, and why scholars focus their research attention on the professional socialization experiences of these individuals.,35-7

The importance of a successful professional socialization experience is founded on the reduction of stress associated with entry into academia. ${ }^{5}$ Early research has found that successful entry into academia is accomplished by using past experiences that translate into knowledge, role congruency, and general acceptance of the role the faculty member will play in the organization. 5,7 When the professional socialization process is effective and successful integration into the faculty role is seamless and less stressful. $1,5,7,8$ Much of the literature on faculty socialization, therefore, has focused on the professional socialization process, yet the organizational stage of socialization can be as impactful on entry into the workforce for the first time. ${ }^{4}$

Organizational socialization can be viewed as the entry phase of the socialization paradigm, whereby the specific values, expectations, and responsibilities of the institution are conveyed to the new faculty member. 4,9 Specific mechanisms used to help a newcomer to the organization often include orientation sessions, developmental workshops, and social networks, which may include peers, mentors, and supervisors. $4,7,10,11$ Some suggest that organizational entry should be facilitated by the individual themselves and that they should be active in their role inductance by being engaged and motivated to participate in activities that support learning the values and norms of the institution. 3,11

Our primary aim was to gain a stronger understanding of the organizational socialization process of junior faculty members entering higher education for the first time. We sought to understand how athletic training faculty members navigate role transition, from doctoral student to faculty member, during the initial entry into higher education (organizational socialization). Current literature, especially in athletic training, has focused more on the experiences prior to entry into higher education (i.e. professional socialization phase), and not as much on actual role transition and the organization's attempts to support it. Our underlying research questions were 1) what organizational processes are present to help transition the pre-tenure faculty member into higher education, and 2) what mechanisms were perceived by the pre-tenure faculty member as helpful in transition into their faculty roles?

\section{METHODS}

\section{Research Design}

We used a qualitative approach to examine the organizational socialization process for junior faculty members in athletic training. ${ }^{12,13}$ An exploratory, general inductive platform was used to better understand the process by which our participants were inducted into higher education and their first faculty member role. The socialization framework was our underpinning, and past research has continually used a qualitative paradigm when using this theoretical framework.

\section{Participants}

Our sampling criteria were purposeful and specific. We sought athletic training faculty members with one to six years of experience in their faculty roles, who had a terminal academic degree, and were pre-tenured but eligible for tenure or promotion. Our inclusion criteria were developed based upon the ideology of role inductance and transition, which is believed to occur during this pre-tenure phase of transition into higher education. After IRB approval we used a convenience and snowball sampling procedure and were able to recruit 19 (13 Female, 6 Male) athletic training faculty members. ${ }^{12,14}$ All met our inclusion criteria, and data saturation was reached. ${ }^{12,14}$ Average age for the Athletic Training faculty members were $32 \pm 3$ years with an average of $10 \pm 3$ years experience as a certified Athletic Trainer. They were employed at various higher education institutions representing a variety of Carnegie Classifications (Table 1). 
Table 1. Individual Faculty Member Demographic Data

\begin{tabular}{|l|c|c|c|c|l|c|c|}
\hline \multicolumn{1}{|c|}{ Name } & Age & Gender & $\begin{array}{c}\text { Years } \\
\text { ATC }\end{array}$ & $\begin{array}{c}\text { Years } \\
\text { Faculty }\end{array}$ & \multicolumn{1}{|c|}{ Current Title } & Carnegie Classification & $\begin{array}{c}\text { NATA } \\
\text { District }\end{array}$ \\
\hline Barbara & 32 & $\mathrm{~F}$ & 10 & 2 & Assistant Professor \& CEC & R2 & 4 \\
\hline Susan & 30 & $\mathrm{~F}$ & 8 & 2 & Assistant Professor & R2 & 8 \\
\hline Scott & 28 & $\mathrm{M}$ & 6 & 1.5 & Assistant Professor \& CEC & M1 & 7 \\
\hline Helen & 36 & $\mathrm{~F}$ & 14 & 4 & Assistant Professor \& CEC & R1 & 9 \\
\hline Frank & 32 & $\mathrm{M}$ & 8 & 3 & $\begin{array}{l}\text { Assistant Professor \& Graduate } \\
\text { Program Director }\end{array}$ & R1 & 4 \\
\hline Betty & 31 & $\mathrm{~F}$ & 8 & 1.5 & Assistant Professor & R1 & 1 \\
\hline Ron & 32 & $\mathrm{M}$ & 9 & 1 & Assistant Professor & R2 & 4 \\
\hline Daniel & 33 & $\mathrm{M}$ & 7 & 1.5 & Assistant Professor & R3 & 10 \\
\hline Laura & 37 & $\mathrm{~F}$ & 15 & 6 & Assistant Professor & $\begin{array}{c}\text { BaccalaureateColleges: } \\
\text { Arts \& Sciences Focus }\end{array}$ & 3 \\
\hline Ruth & 34 & $\mathrm{~F}$ & 12 & 2 & Assistant Professor \& CEC & M1 & 1 \\
\hline Cindy & 30 & $\mathrm{~F}$ & 8 & 2 & Assistant Professor & $\begin{array}{c}\text { Baccalaureate } \\
\text { Colleges: Diverse }\end{array}$ & 1 \\
& & & & & & Fields & M1 \\
\hline Michelle & 32 & $\mathrm{~F}$ & 10 & 9 & $\begin{array}{l}\text { Assistant Professor, Director AT } \\
\text { Program }\end{array}$ & 3 \\
\hline Margaret & 34 & $\mathrm{~F}$ & 12 & 1 & Assistant Professor & M1 & 2 \\
\hline Joyce & 29 & $\mathrm{~F}$ & 7 & 1 & Assistant Professor & M1 & 3 \\
\hline Heather & 32 & $\mathrm{~F}$ & 9 & 3 & Assistant Professor \& CEC & M1 & 9 \\
\hline Christine & 33 & $\mathrm{~F}$ & 11 & 4 & Assistant Professor \& CEC & M1 & 3 \\
\hline Gloria & 40 & $\mathrm{~F}$ & 18 & $<1$ & Assistant Professor & M1 & 8 \\
\hline Thomas & 32 & $\mathrm{M}$ & 9 & $<1$ & Assistant Professor & R2 & 4 \\
\hline Josh & 27 & $\mathrm{M}$ & 6 & $<1$ & Assistant Professor & R3 & 4 \\
\hline
\end{tabular}

Note: $\mathrm{CEC}=$ Clinical Education Coordinator

\section{Data Collection.}

Interviews were conducted with all participants over the phone. The semi-structured nature of the interview protocol (Appendix) was purposeful, as we wanted the chance to dialogue back and forth with the participant as a means to understand their experiences related to their organizational socialization process. Prior to our data collection process, we developed the interview protocol by using the existing literature on organizational socialization, our experiences as faculty members, and the overall purpose of the study. An expert in the field of qualitative research, faculty development, and higher education reviewed the initial protocol. ${ }^{3-5,15,16}$ The expert confirmed its content and made a few recommendations to improve the flow and clarity of the questions. Then two faculty members in athletic training were interviewed as a pilot study to finalize the interview framework prior to data collection; one met our criteria and the other was knowledgeable in qualitative methods but did not have a tenure-earning position. No edits or changes resulted from this process, and the data collected within the pilot study were included in our analysis of the data. Each interview session lasted approximately 40 minutes. We had an independent transcription company transcribe all interview sessions verbatim.

\section{Data Analysis and Credibility}

Our coding process began with an immersive approach whereby all transcripts were read multiple times allowing the researchers to gain acclimation and understanding. The general inductive approach emphasizes the organic process of allowing the key findings to emerge through the reading of the data. ${ }^{12,13}$ From this process, we were able to draw out the dominant findings, which were identified as common and consistent among the participants. Labels were applied to these common findings as a means to capture their overall meaning, and then they were grouped together with a final code to represent the content and overall theme.

We selected 3 primary mechanisms to secure our credibility: 1) peer review, 2) multiple analyst triangulation, and 3) interpretative member checks. ${ }^{12}$ The peer review occurred prior to data collection and included the steps described regarding the interview protocol development. We completed the coding process with two researchers independently coding the data following the steps outlined in the previous section. Prior to coding, both researchers discussed the sequential steps to code the data. Each researcher 
has previous training and experience in general inductive analyses. Once coding had been completed, the researchers exchanged a coding schematic, including sample coded data and operational definitions of those codes. The exchange resulted in the presentation of findings below. Finally, as we wanted to ensure that we captured the true organizational socialization process of our participants, we asked two participants to review our results and confirm its accuracy. This form of interpretive member check served as a means to provide rigor and credibility to our findings.

\section{RESULTS}

Two primary mechanisms (figure 1) were identified as socializers for the athletic training faculty member as they transitioned into their faculty roles. From our analyses, we defined organizational mechanisms as those that were institutionally driven and facilitated by the higher education institution itself. Individual mechanisms were those aspects of the transition process, which were facilitated by the individual faculty member. Each primary mechanism was supported by 4 and 2 distinct components, respectively, that we describe in detail with supporting quotes next.

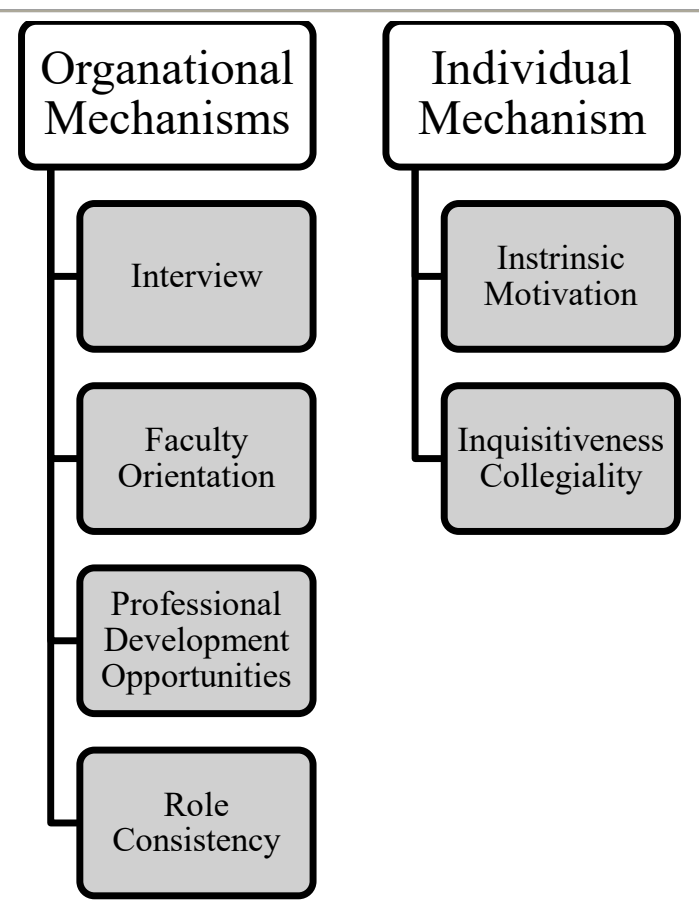

Figure 1. Organizational and Individual Mechanisms Supporting Organizational Socialization

\section{Organizational Mechanisms}

Organizational mechanisms speak globally to the formal activities sponsored by the faculty member's university as a means to support role acclimation, role transition, and success as a faculty member. For our athletic training faculty, these organizational mechanisms were described as 1) the job interview, 2) the faculty orientation, 3) professional development opportunities and 4) role consistency. Table 2 provides supporting quotes, in addition to those included in the text that follows. 
Table 2. Organizational Mechanisms to Role Transition

Organizational Mechanisms

\section{The Interview}

During my initial conversations with the department chair, I discovered for that first year what my role and responsibilities would be. I had some understanding prior to that through the contract for the actual position [document shared during the interview]. When I accepted the position itself, it was very specific about how many courses I would be teaching, all of the advisees that I would have, what service, and what level of service responsibilities and research I would have. Joyce

I asked a lot of question during my interview and a lot of information was given about what the position was looking like which I interviewed. Laura

\section{Faculty Orientation}

We have a new faculty retreat, which is a three-day thing where faculty members prior to their first year attend. Most of it is going over university policies, Human Resource information, Title 9 , kind of all the big concept things, and then as part of that, you break out into your different colleges that you're a part of and you get a little more specific on what those colleges expect. $\sim$ Scott

I had to go to a faculty orientation, which was about two and a half days. It was a chance for the distribution of a bunchy of documents and handouts and helpful websites. The orientation sessions, delivered by human resources, included a vast number of people from different avenues who provide lectures and presentations. Thomas

There was an orientation. There was a new faculty orientation. That lasted, I believe it was 2 days long. Fairly continuous each day, l'd probably say about 9 to 5 or so for a couple of days before courses, classes started in the fall. And that was on your general policies and procedures regarding the campus and the inter-workings of the campus. Cindy

\section{Professional Development}

My university does offer these satellite workshops after the orientation if there are specific areas or topics that you feel like you need to focus specific information on or advice. The have some panel discussions that you can go to and more directly ask questions to both successful junior faculty or senior faculty who are on the university committee for decision-making on reappointment or tenure. I get emails every other week that something is going on that relates to that topic. $\sim$ Frank

We have a faculty center for teaching excellence, and they put on workshops at least once a week, and they have newsletters that go out. So, I spend a lot of time there. Josh

I attend as many faculty development workshops a semester as I can, to help me get it. Things like just reviewing, getting feedback on CVs, to presentation style workshops, to teaching workshops. Talked about learning styles, personality styles, I guess, and conflict resolution. Susan

The Office of Sponsored Programs does put on seminars on grant writing. I've gone to those and ... had a few people come in who have received a new investigator or a young investigator grants through NIH and NSF and I went to those. So there is a pretty good support system. Helen

\section{Role Consistency}

My expectations are about the same [as they were] last year. It might change slightly next year because the university does give new faculty release time within the first two [years]. In my contract, there was release time in the first two years when we're establishing a research line. So next year that might be up for debate, but l've heard confirmation 
verbally from the department chair and dean that if I'm being productive with research, I'm going to stay at my current teaching load but there's nothing confirmed so that might change. Helen

I am teaching the same courses as last year, so nothing will be from scratch, which is really nice. Gloria

\section{The Interview}

Some of the participants discussed the importance of the job interview as their first method of becoming acquainted with the roles and responsibilities of their faculty positions. Barbara shared that she was poised to "ask a lot of questions during the interview process." She shared asking to see "the job description" as her first attempts to become aware of the expectations. Cindy also felt as though "my interview for the faculty position," was her first step in her on-boarding process. Others like Barbara and Cindy felt as though they were able to get first-hand information during the interview, which was helpful in becoming familiar with the institution and the associated faculty roles they would assume. For some, the on-boarding process began prior to the first day on the job but was very specific to the job descriptions that accompanied their faculty position. The interview served as a formal mechanism for the institution to describe and convey the expectations specific to the position for which they were interviewing.

\section{Faculty Orientation}

All 19 of our participants recognized faculty orientation as organizational socialization tactic used to help transition them into their positions as a faculty member. The common response, when asked about how they were made aware of their expectations, was "new faculty orientation" or "orientation." Many of our participants described the new faculty orientation as a "focused, single event" that was often hosted by human resources to cover "a broad spectrum of topics, including benefits, expectations, and other important things related to the university system. (Margret)"

Although most faculty orientations were described as one-day events, several did describe longer events, usually 2-3 days in length, that were comprehensive sessions. As stated by Frank, who described a process that persisted over 2 days "the general orientation for the department, and then another one for the college helps you to understand teaching expectations and what's required, the baseline, what's expected of you as an instructor of a course, and then from a research perspective." The faculty orientation sessions were reflective of a one-time informative mechanism to share important university and human resource policies to the faculty.

\section{Professional Development}

Faculty development opportunities were also shared by our participants as formal avenues for learning more about their roles as faculty, specifically related to the teaching and research aspects of their roles. Unlike the faculty orientation sessions, these offerings were often voluntary and communicated to the general faculty via list serves or emails. Although our pre-tenured faculty discussed capitalizing on them, they appeared to be offered to the general faculty, not just new faculty. Cindy discussed learning more about what was expected of her as a faculty member by saying, "They [the university] hold faculty development seminars; I think there's probably about between 6 and 10 each semester." When asked about how she was made aware of them she said, "emails, list serves, and word of mouth."

Professional development opportunities were described as formal activities, often in the format of workshops or seminars, which could facilitate skill or knowledge development in specific pillars related to teaching, research, and navigating promotion and tenure. Susan discussed a faculty writing group that was offered as a professional development opportunity. She shared, "the Provost supports young faculty, you meet once a week, and you set the time." When asked to discuss the writing group Susan offered, "it was driven by the group, we set the pace. It was not a peer edit, but rather accountability for consistency."

The faculty development opportunities were formal but included voluntary activities designed to support the faculty members' transition as well as the development of skills necessary to navigate their jobs. Unlike the orientation sessions, these were directed experiences that occurred over time, were focused on certain topics, and communicated to the university-wide community and was independent of the first few weeks of employment.

\section{Role Consistency.}

Our participants described that during their first few years in their current faculty role, it remained steadfast, and that many of their responsibilities were consistent from year to year. The consistency afforded to them by their supervisors regarding teaching, advising, research, and service supported their transition and socialization into higher education. When asking our participants to discuss their transition, we heard them detail uniformity in their expectations during the first few years as offered by Frank who 
said, "my current position hasn't changed much. I am actually teaching the same and have some research release too." A few participants described the idea of "being protected during the first few years" as a tactic to allow for the faculty member to "get settled in" without too much change during the first few years as they transitioned. Several of our participant's experiences reflect the ideology of consistency to allow for the junior faculty member to succeed as they navigate their new role.

\section{Individual Mechanisms}

Individual mechanisms speak to the attributes of our participants, whereby they displayed inherent motivation to learn about the expectations of their new roles as well as solicited guidance that mimicked informal mentoring. Table 3 provides supplemental quotes to support our findings.

Table 3. Individual Mechanisms Assisting Role Inductance

\section{Individual Mechanisms}

\section{Intrinsic Motivation}

When I see something that I think is going to be worthwhile or interesting, I definitely go and seek that out. There are no specific expectations other than tenure and professional review to really say we have to attend this certain number of those classes and most of our faculty went. So, there's definitely that aspect, but also, I mean, I kind of want to be a better professor, better teacher, better mentor so, professionally. Personally, it was of interest. Scott

I wanted to learn more, so I can succeed. I listen to podcasts a lot like different teaching and higher-education podcasts and research podcasts. It's not formal, but that would be the only source. And it's been a good source of information and support outside of my university. I want to. It was my motivation to participate. Susan

I have taken workshops on blackboard, student writing, and other aspects to faculty roles. I actually applied to be in a new PT academy, a formal mentor program. I thought it would be a good idea to see different things, get an outside perspective from a mentor program. Someone who could help me focus, get over some hurdles - it assists with grand writing, IRB, funding, etc.... I thought it was a good idea. I wanted to be better at all things faculty. Barbara

\section{Inquisitiveness and Collegiality}

My two co-workers that I work with primarily in my [AT] program. Just asking them questions, constantly asking them what the requirements were, what I should be doing, how much research do I need. Josh

Asking a lot of question. Yeah, I mean, really I didn't know a lot when I came in and I felt a little blind, but asking a lot of question I luckily had my program director is younger as well and is on a tenure-track position as well, so I felt like I asked her a lot of questions and she was really helpful with things. Heather

You know, what I have found to be most helpful is just being able to talk to other professionals who are in the same place in their careers. So, even if it was, you know, whether it's in person, or online, just being able to have another ear to bounce ideas off or get suggestions. I think that has been helpful. Daniel

\section{Intrinsic Motivation to Learn and Succeed}

During the interview sessions, our participants shared wanting to "engage in" activities that would assist them in transitioning and allowing them to better understand the culture regarding the faculty role. The discussions were focused on participating as Helen described, "in as many professional development things I can. As it can only help me." Helen continued to share "I want to do better (as a faculty member). I want to be better at everything. I want to learn. I want to meet more researchers within the community. I want to expand my teaching skill sets. Everything that I've participated in is supposed to be somehow just selfimprovement really." Helen's declaration epitomized that idea of intrinsic motivation and a commitment to learning. Self-reflections of our participants included descriptors such as "self-motivated." The desire to be a better faculty member was the motivation to seek learning opportunities that would support this initiative. The professional activities were often voluntary, and thus required a degree of commitment and motivation. 


\section{Role Learning Through Individual Inquisitiveness and Collegiality}

Professional discourse emerged as a mechanism to become acclimated to faculty life, and how our participants learned more about the expectations related to their faculty positions. The discourse was founded on the participant's inquisitiveness and desire to learn more. Cindy's strategy to become more familiar with her role was to "get to know the other faculty members here." She continued that her "current colleagues were very informative and they were very honest and very thorough about what exactly they would want me to do." Their conversations, in Cindy's opinion, were very helpful in her transition. Dialogue with colleagues repeatedly surfaced from the interview sessions as a means to gain clarity on their role and the expectations that can be associated with faculty status. Soliciting advice and guidance from other faculty was deemed as an important organizational socialization tactic.

\section{DISCUSSION}

Organizational socialization is an important part of a new faculty member's acclimation into higher education, as it helps provide a clear understanding for success. The transition into higher education has been described as stressful, and at times overwhelming, because the new faculty member must navigate institutional expectations as well as establish their own professional identity. ${ }^{17}$ Our findings illustrate the role the organization plays in socializing the new faculty member, but also the responsibility the individual faculty member has in transitioning.

\section{Organizational Mechanisms}

New faculty orientation seminars, professional development workshops, and mentor programs provide the platform for organizational tactics to assimilate new faculty into their roles in higher education. $16,18,19-21$ So, finding that our participants reported these same avenues is not surprising. These formalized institutional mechanisms are designed to convey information on departmental and university policies and procedures, which is believed to help support role inductance into the new work environment. ${ }^{22,23}$

In alignment with the recent work of Mazerolle and peers, we found that institutional mechanisms were available to the transitioning faculty member. ${ }^{18}$ Our participants described structured experiences that were designed to communicate specific information regarding university policies and benefits, expectations related to tenure and promotion, and the overall responsibilities of the faculty member. Although the job interview is often viewed as an independent experience from the organizational socialization process, our participants felt as though it was the first step towards role inductance and acculturation, as it outlined their roles and responsibilities. In principle, the job interview is comparable to a faculty orientation, as it is founded on disseminating key information to allow the new employee to be successful. We encourage faculty members to use the interview process effectively to gain an understanding of organizational expectations before accepting a position.

Role inductance encompasses the new faculty member developing their identity as they accumulate experiences that allow them to appreciate the values, norms, and culture of the institution, itself. ${ }^{4}$ The concept of role consistency emerged as a new finding that offered our faculty a chance to remain steadfast in their roles. The consistency within their position meant that they were able to gain their footing and feel as though they were being successful in the role, as nothing was changing. Therefore, we suggest that as part of the inductance process, the use of consistency with job expectations may assist the faculty member in being successful in assimilating into the role, as it can reduce stress and increase understanding.

\section{Individual Mechanisms}

Institutions must facilitate and support organizational socialization. However, some researchers contend that the first socializing agent is the person themselves, as they must take an active role in learning what is expected of them and how they will function within the organization. 3,10,24 We found that our participants were active in their role transition and that they solicited information from colleagues as a means to successfully support their transition. Mentorship is commonplace in higher education and is often described as an organizational socializer as the mentor shares their knowledge or culture, politics, and the philosophy of the organization. ${ }^{25}$ Our participants described gaining their foothold on the expectations and the subtle culture regarding their expectations for success, and having someone who could guide them was viewed as beneficial -- a finding that has been reported previously as part of the socialization process. ${ }^{18,26}$ Moreover, the socialization process is founded by the social interactions among the stakeholders in the organization, thus it is not surprising that our participants linked this to their role inductance process ${ }^{4}$ There is value in learning by observing, and this can offer the new faculty member the chance to gain role understanding organically, and without much effort. ${ }^{18,27}$ Faculty members should take initiative to seek mentors and participate in organizational resources that help them understand their roles and responsibilities and institutional expectations. 
Our participants also displayed intrinsic motivation and eagerness to better understand how to succeed in their new role. This is not surprising, as often, athletic trainers are described as self-motivated. ${ }^{28}$ Recently it was found that new faculty in athletic training actively seek professional development opportunities as a means to gain competence in their new faculty roles. ${ }^{29}$ From a developmental standpoint, our participants' self-reported motivation indicates the recognition for the development of competence, which may be socially driven by actively engaging with work communities. ${ }^{30}$ Acclimating into higher education, as shared by our participants, is partially supported by a process of interacting and seeking answers from co-workers as well as taking advantage of professional development activities that directly relate to faculty roles.

\section{Limitations and Future Directions}

We provide our findings from the perspective of the pre-tenure faculty member in a specific health care discipline. We believe that our data speaks to a more global perspective but are cognizant that our findings may not fully capture others' experiences. Athletic training is a discipline that is comparable to programs such as physical therapy, allied health, and nursing, yet the experiences of the faculty member may be different as each may have unique requirements. We did not make any comparisons in terms of the Carnegie classification of the participant. That is, we did not try to understand whether organizational socialization mechanisms may differ based upon the categorization, or how past educational experiences influenced the organizational socialization process.

We used a qualitative platform to explore organizational socialization and assimilation for the faculty member. Our findings provide some basic understanding of the process, but future research may broaden the scope of study by including a larger sample, comparisons among other medical and healthcare disciplines, and a metric of organizational assimilation and socialization.

\section{CONCLUSIONS}

Athletic training faculty new to their role identify several organizational mechanisms in which they were acclimated to their role. The finding that professional development workshops and faculty orientation sessions were used as formal means to initiate the inductance process was not unexpected but does validate their importance in the process. Many of these activities are voluntary but can be highly important in the beginning stages of the new faculty's acculturation process. Having consistency in one's role, during the early stages of the job can support early success of the inductance process. Supervisors and administrators should recognize the need for consistency, or in some cases, provide progressive increases in expectations of the junior faculty member. For example, institutions may offer reduced workloads or try to shield the new faculty member in regard to early service requirements; these statics can reduce the stress and allow for the faculty member to fully appreciate the effort and time needed for the main aspects of the faculty role. The new faculty member should take advantage of the formal mechanisms offered by their institutions, but must also be proactive, have self-motivation, and be an observer of their surroundings.

Note: This study was funded by the National Athletic Trainers' Association Research and Education Foundation research grant \#1516EGP003.

\section{References}

1. Van Maanen J, Schein IH. Toward a theory of organizational socialization. Res Organ Behav. 1979;1:209-264.

2. Feldman DC. A contingency theory of socialization. Adm Sci Q. 1976;21:433-452.

3. Tierney WG, Rhoads RA, eds. Faculty socialization as a cultural process. 6th ed. Washington, DC: ASHE-ERIC Higher Education Report; 1994 Enhancing Promotion, Tenure and Beyond; №. 93.

4. Tierney WG. Organizational socialization in higher education. J Higher Educ. 1997;68(1):1-16

5. Austin AE. Preparing the next generation of faculty: Graduate school as socialization to the academic career. J Higher Educ. 2002;73(1):94-122.

6. Austin A , McDaniels M. Using doctoral education to prepare faculty to work within Boyer's four domains of scholarship. In: Braxton J, ed. Delving further into Boyers's perspective on scholarship. Vol 129. San Francisco, CA: New Directions for Institutional Research; 2007:51-65.

7. Bowman TG, Klossner JC, Mazerolle SM. The Doctor of Philosophy Experience of Athletic Trainers: Facilitators and Barriers to Anticipatory Faculty Socialization. J Athl Train. 2017;52(10):925-936. doi:10.4085/1062-6050-52.7.01

8. Sorcinelli MD, Austin A , Eddy PL, Beach AL. Creating the future of faculty development: Learning from the past, understanding the present. San Francisco, CA: Jossey-Bass; 2006.

9. Bergquist WH, Pawlak K. Engaging the six cultures of the academy: Revised and expanded edition of the four cultures of the academy. San Francisco, CA: Jossey-Bass; 2007. 
10. Fisher CD. Organizational socialization: An integrative review. Res Person Hum Resour Manag. 1986;4:101-145.

11. Turner CSV, Thompson JR. Socializing women doctoral students: Minority and majority experiences. Rev High Ed. 1993;16(3):355-370.

12. Creswell JW. Qualitative inquiry \& research design. 3rd ed. Thousand Oaks, CA: SAGE; 2013.

13. Thomas D. A general inductive approach for qualitative data analysis. American Journal of Evaluation. 2006;27:237246.

14. Merriam SB. Qualitative research: A guide to design and implementation. San Francisco: Jossey Bass; 2009.

15. Nottingham SL, Mazerolle SM, Barrett JL. Promising and Established Investigators' Experiences Participating in the National Athletic Trainers' Association Foundation Research Mentor Program. J Athl Train. 2017;52(4):368-376. doi:10.4085/1062-6050-52.2.11

16. Mullen CA, Forbes SA. Untenured faculty: Issues of transition, adjustment and mentorship. Mentoring \& Tutoring: Partnership in Learning. 2000;8(1):31-46.

17. Lichty M. The socialization process of new college faculty in family and consumer science teacher education. [Ph.D.]. Virginia Tech; 1999.

18. Mazerolle SM, Barrett JL, Nottingham SL. Examining the factors that facilitate athletic training faculty socialization into higher education. Athl Train Educ J. 2016;11(4):208-218.

19. Cawyer CS, Simonds C, Davis S. Mentoring to facilitate socialization: The case of the new faculty member. Int J Qual Stud Educ. 2002;15(2):225-242.

20. Stupnisky RH, Weaver-Hightower MB, Kartoshkina Y. Exploring and testing the predictors of new faculty success: A mixed methods study. Studies in Higher Education. 2015;40(2):368-390.

21. Morin $\mathrm{KH}$, Ashton KC. Research on faculty orientation programs: Guidelines and directions for nurse educators. Journal of Professional Nursing. 2004;20(4):239-250.

22. Cawyer CS, Friedrich GW. Organizational socialization: Processes for new communication faculty. Comm Educ. 1998;47(3):234-245.

23. Kramer MW, Miller VD. A response to criticisms of organizational socialization research: In support of contemporary conceptualizations of organizational assimilation. Communication Monographs. 1999;66(4):358-367.

24. Tierney WG. Organizational culture in higher education: Defining the essentials. J Higher Educ. 1988;59(1):2-21.

25. Rawlings M. What is mentoring? http://www.edu.salford.ac.uk/scd/ documents/docs/Mentoringonlinepaper.rtf. Accessed July 21, 2017.

26. Dubetz N, Turley S. Mentoring in higher education: A self-study of faculty socialization. Networks. 2001;204(1):1-7.

27. Golde CM. Applying lessons from professional education to the preparation of the professoriate. New Directions for Teaching and Learning. 2008;113:17-25.

28. Pitney WA. A qualitative examination of professional roll commitment among athletic trainers working in the secondary school setting. J Athl Train. 2010;45(2):198-204.

29. Kilbourne BF, Bowman TG, Mazerolle SM. A developmental perspective on behaviors of new faculty transition into higher education. J Athl Train. 2018;13(4):348-358.

30. Paloniemi S. Experience, competence and workplace learning. Journal of Workplace Learning. 2006;18(7/8):439-450.

(C) The Internet Journal of Allied Health Sciences and Practice, 2019 


\section{Appendix: Interview Protocol}

1. How did you learn what was expected of you in your faculty role?

2. Did you participate in formal activities to learn more about your roles and responsibilities?

3. Are there other ways you learned about the roles and responsibilities of your position?

4. Were you satisfied with the ways in which you learned about your roles and responsibilities? Please describe.

5. Besides a faculty orientation, have you participated in any other faculty development at your institution?

a. Can you describe them?

b. Can you share what motivated you to participate in them?

c. If you have not participated in any other faculty development activities, would you be interested in them? Explain.

6. Besides a faculty orientation, have you participated in any other faculty development activities external to your institution?

a. Can you describe them? Can you discuss how you learned about them?

b. Can you share what motivated you to participate in them?

c. If you have not participated in any other faculty development activities, would you be interested in them? Explain. 